Jurnal PG-PAUD Trunojoyo : Jurnal Pendidikan dan Pembelajaran Anak Usia Dini, Volume 7, Nomor 2, Oktober 2020 hal 69-74, ISSN : 2528-3553 (online), ISSN: 2407-4454 (print)

\title{
KEMAMPUAN BERPIKIR SIMBOLIK ANAK MELALUI BERMAIN DENGAN MEDIA STICK ANGKA
}

\author{
Veryawan ${ }^{1}$ \\ 'PIAUD, Institut Agama Islam Negeri Langsa \\ Email:veryawan@iainlangsa.ac.id \\ Received (Juni), Accepted (September), Published (Oktober)
}

\begin{abstract}
Children's Symbolic Thinking Ability Through Playing With Number Stick Media. This study has the aim of improving the symbolic thinking skills of children through playing with the number stick media. The purpose of this study was to determine the symbolic thinking ability of group B children at Islamic Kindergarten Al Jihad increased after using the number stick media. The subjects of this study were 15 children of group B at Al Jihad Kindergarten in Sei Rampah Village, Sei Rampah District, Serdang Bedagai Regency. This research was conducted in two cycles with 4 treatments in each cycle, namely planning, implementing, observing and reflecting. The data obtained were analyzed through two data analysis techniques, namely qualitative and quantitative data analysis techniques. The indicators to be achieved in this research are mentioning number symbols, counting, connecting images according to number symbols. The results of the study before the first cycle of 15 children, there were only $20 \%$ of children who achieved success indicators, then after taking action treatment in cycle I, of the 15 children who achieved success indicators in this study, namely (BSH) developed according to expectations, namely $47 \%$. In the second cycle, of the 15 students who achieved the indicator of success in this study, namely (BSH) developed according to expectations, namely 93\%. Thus, it can be concluded that playing with number stick media can be an alternative to improve children's symbolic thinking skills in recognizing number symbols.
\end{abstract}

Keywords: symbolic thinking, playing, stick figure media, children

Abstrak: Kemampuan Berpikir Simbolik Anak Melalui Bermain dengan Media Stick Angka. Penelitian ini mempunyai tujuan yaitu untuk meningkatkan kemampuan berpikir simbolik anak didik melalui melalui bermain dengan media stick angka. Tujuan dari penelitian ini adalah untuk mengetahui kemampuan berpikir simbolik anak didik kelompok B TK Islam Al Jihad meningkat setelah menggunakan media stick angka. Subjek penelitian ini adalah anak didik kelompok B TK Islam Al Jihad Desa Sei Rampah Kecamatan Sei Rampah Kabupaten Serdang Bedagai, sebanyak 15 orang. Penelitian ini dilaksanakan II siklus dengan 4 perlakuan pada setiap siklusnya yaitu perencanaan, pelaksanaan, pengamatan dan refleksi. Data yang didapatkan dianalisis melalui dua teknik analisis data, yakni teknik analisis data kualitatif dan kuantitatif. Indikator yang ingin dicapai dalam penelitian ini yaitu menyebutkan lambang bilangan, menghitung, menghubungkan gambar sesuai dengan lambang bilangan. Hasil penelitian pada sebelum siklus I dari 15 anak didik, hanya terdapat $20 \%$ anak didik yang mencapai indikator keberhasilan, kemudian setelah dilakukan perlakuan tindakan pada siklus I, dari 15 anak didik yang mencapai indikator keberhasilan pada penelitian ini yaitu (BSH) berkembang sesuai harapan yaitu 47\%. Pada siklus II, dari 15 anak didik yang mencapai indikator keberhasilan pada penelitian ini yaitu (BSH) berkembang sesuai harapan yaitu 93\%. Dengan demikian maka dapat disimpulkan bermain dengan media stick angka dapat menjadi salah satu alternatif untuk meningkatkan kemampuan berpikir simbolik anak dalam mengenal lambang bilangan.

Kata kunci: berpikir simbolik, bermain, media stik angka, anak 
Jurnal PG-PAUD Trunojoyo : Jurnal Pendidikan dan Pembelajaran Anak Usia Dini, Volume 7, Nomor 2, Oktober 2020 hal 69-74, ISSN : 2528-3553 (online), ISSN: 2407-4454 (print)

\section{PENDAHULUAN}

Pendidikan anak usia dini sangatlah penting, karena pertumbuhan dan perkembangan seorang anak akan dapat berkembang sesuai dengan karakter dan kebutuhan melalui program pembelajaran yang dirancang oleh suatu lembaga pendidikan. Beichler dan Snowman (Yulianti, 2010) mengatakan bahwa usia dini adalah anak usia 0-6 tahun atau masa keemasan (golden age).

Anak usia dini memiliki karakteristik yang unik baik secara fisik, sosial, emosi, kognitif dan spiritual yang saling berkaitan erat satu sama lain (Nuryani, 2020). Masa usia dini merupakan masa paling penting bagi anak untuk sepanjang hidupnya, karena pada masa ini adalah masa pembentukan pondasi dan dasar kepribadian yang akan menentukan pengalaman anak selanjutnya (Hasnida, 2014).

Anderson (Ayuni \& Setiawati, 2019) sebagaimana dikemukakannya "Early childhood education is based on a number of methodical didactic consideration the aim of which is provide opportunities for development of children personality". Artinya, pendidikan untuk anak usia dini seyogianya memberikan kesempatan pada anak dengan melakukan banyak kegiatan yang dapat mengembangkan seluruh aspek perkembangan dan kepribadian anak.

Aspek perkembangan kognitif merupakan upaya kemampuan berpikir anak sehingga dapat berkembang secara menyeluruh di pusat syaraf berfikir anak didik. Kemampuan kognitif akan mengalami perkembangan secara bertahap seiring dengan perkembangan dan pertumbuhan fisik dan pusat susunan syaraf. Menurut Suardiman (Gandana et al., 2017) mengungkapkan bahwa kemampuan kognitif atau kemampuan berpikir dapat berkembang apabila banyak didukung dengan kemampuan bertanya dan mengamati hubungan kegiatan sehingga memperoleh banyak pengetahuan baru.

Menurut Piaget (Astuti, 2013), melalui perkembangan kemampuan kognitif anak akan mampu berpikir simbolik, memecahkan masalah dan mengingat sesuatu. Kemampuan berpikir simbolik adalah salah satu dari berbagai aspek penting yang dimiliki oleh anak. Menurut piaget objek dan peristiwa secara nyata (fisik) tidak hadir dihadapan anak, merupakan kemampuan berpikir simbolik tentang objek dan peristiwa (Bodedarsyah \& Yulianti, 2019). Tahap simbolik merupakan tahap belajar mengenai suatu konsep. Suatu konsep yang mereka pelajari agar dapat mengetahui suatu objek tetapi tidak sesuai dengan objek kenyataan. Konsep ini penting untuk dipelajari karena akan menjadi bekal anak pada kehidupan dan pendidikan selanjutnya (Hardiyanti et al., 2018).

Menurut Mutiah (2010) mengungkapkan bahwa pemikiran praoperasional merupakan subtahap fungsi simbolik. Anak menggunakan simbol-simbol terhadap suatu objek atau perlakuan dalam mempresentasikan sesuatu yang tidak ada dihadapan mereka maka kemampuan berpikir simbolik sedang terjadi pada anak. Tahap simbolik merupakan tahap belajar mengenai konsep. Konsep dipelajari agar mereka dapat mengenal suatu objek namun tidak bergantung dengan objek nyata (Hardiyanti et al., 2018).

Kegiatan belajar pada anak harus melalui bermain, karena bermain merupakan dunia anak. Kebutuhan psikologis dan biologis yang sangat penting bagi seorang anak dapat tersalurkan melalui kegiatan bermain. Bermain merupakan sarana hiburan bagi anak yang memiliki tujuan, baik untuk tubuh dan pikiran anak (Amiran, 2016). Bermain juga bermanfaat untuk mencerdaskan otak dan proses berpikir seorang anak akan berkembang melalui bermain. Perkembangan intelektual akan memperkaya pola berpikir dengan melakukan berbagai pengalaman merupakan kontribusi dari kegiatan bermain (Farhurohman, 2017). 
Jurnal PG-PAUD Trunojoyo : Jurnal Pendidikan dan Pembelajaran Anak Usia Dini, Volume 7, Nomor 2, Oktober 2020 hal 69-74, ISSN : 2528-3553 (online), ISSN: 2407-4454 (print)

Pengembangan berpikir simbolik anak memerlukan strategi dan media pembelajaran yang tepat agar berhasil maksimal dalam pembelajaran. Salah satu media yang dapat dipergunakan untuk meningkatkan kemampuan berpikir simbolik anak adalah melalui media stick angka. Bentuk media pembelajaran berlandaskan permainan yang bertujuan untuk menyampaikan suatu kegiatan pembelajaran pada peserta didik adalah permainan stick angka.

Penerapan permainan stick angka diharapkan dapat mempermudah anak didik dan lebih termotivasi dalam kegiatan belajar memahami konsep bilangan. Permainan stick angka terbuat dari tongkat, batang atau potongan kayu yang digunakan dalam penelitian ini dijadikan sebagai sarana bermain dan berhitung (Ayu et al., 2011). Permainan ini cukup mudah, hanya dengan menggunakan dan mempersiapkan beberapa stick es krim bekas ataupun yang baru, lambang bilangan yang sudah dibuat dari kardus, karton atau kertas. Stick berarti tongkat, batang ataupun potongan. Sedangkan angka adalah simbol hitungan pokok dari 0 s/d 9.

Stick angka merupakan sejumlah stick yang bertuliskan simbol angka pada setiap stick. Media stick angka adalah media yang terbuat dari potongan kayu (Abubakar et al., 2018). Media stick ini merupakan media pengganti balok. Media edukatif dengan biaya murah, maka peneliti mengganti balok dengan stick es krim yang mudah di cari dan digunakan yaitu beberapa stick es krim bekas ataupun baru. Untuk membuat media stick angka menurut Sujiono dkk (2011: 49) dibutuhkan alat dan bahan yang mudah didapat, diantaranya yaitu : stick es cream, gunting, kertas lipat, gambar benda dan sterofoam.
Kenyataan di lapangan menunjukkan bahwa banyak anak yang belum bisa menyebut dan menggunakan lambang bilangan secara sempurna, ini dibuktikan dari hasil observasi peneliti di TK Islam Al Jihad Desa Sei Rampah Kec. Sei Rampah Kab. Serdang Bedagai, dengan jumlah anak 15 orang, 10 anak laki-laki dan 5 anak perempuan, setelah didata dan dinilai kemampuan berpikir simbolik anak masih kurang karena baru 3 orang anak (20\%) mampu menyebut, berhitung dan mencocokkan lambang bilangan 1-10, anak sebahagian mampu menyebutkan namun tidak sepenuhnya mengerti apa yang disebutnya, masalah ini bisa disebabkan oleh beberapa faktor diantaranya media yang digunakan guru dalam memperkenalkan lambang bilangan kurang menarik sehingga anak menjadi bosan dan kurang minat belajar.

Dengan keadaan demikian, peneliti berusaha untuk menyediakan media pembelajaran yang menarik dan edukatif agar kegiatan pembelajaran berjalan sistematis dan mencapai tujuan pembelajaran. Untuk itu, mengingat pentingnya suatu media yang dibuat dan dimiliki oleh peneliti, maka dari itu peneliti melakukan suatu penelitian dengan judul Peningkatan Kemampuan Berpikir Simbolik Anak Usia 5-6 Tahun Melalui Bermain dengan Media Stick Angka di TK Islam Al Jihad Desa Sei Rampah Tahun Ajaran 2018/2019.

\section{METODE PENELITIAN}

Dalam penelitian ini mengunakan metode penelitian tindakan kelas yang terdiri dari II siklus. Penelitian ini dilakukan di Kelompok B TK Islam Al Jihad Desa Sei Rampah Kecamatan Sei Rampah Kabupaten Serdang Bedagai. Penelitian ini dilaksanakan pada 
Jurnal PG-PAUD Trunojoyo : Jurnal Pendidikan dan Pembelajaran Anak Usia Dini, Volume 7, Nomor 2, Oktober 2020 hal 69-74, ISSN : 2528-3553 (online), ISSN: 2407-4454 (print)

Semester II Tahun Pelajaran 2018/2019 dan waktu penelitian dijadwalkan: Senin-Jum'at, mulai tanggal 22 April sampai dengan 04 Mei 2019. Subjek penelitian adalah murid kelompok B TK Islam Al Jihad Desa Sei Rampah Tahun Pelajaran 2018/2019, yang berjumlah 15 anak didik terdiri dari 10 anak didik laki-laki dan 5 anak didik perempuan. Dalam pengumpulan data menggunakan tehnik observasi, wawancara, dokmentasi dan tes. Dalam menyajikan hasil analisis yang dilakukan pada proses kegiatan berlangsung dengan media stick angka, peneliti menggunakan analisis presentase untuk memperoleh hasil tentang meningkatkan kemampuan berpikir simbolik anak melalui bermain stick angka dan tes analisis dengan menggunakan nilai rata-rata anak serta kriteria ketuntasan belajar anak. Penelitian ini dianggap berhasil apabila telah mencapai 80\% dalam melakukan pengembangan berpikir simbolik anak melalui kegiatan bermain dengan media stick angka.

\section{HASIL DAN PEMBAHASAN}

Sebelum kegiatan siklus I dilaksanakan, diketahui bahwa kemampuan berpikir simbolik anak di Kelompok B TK Islam Al Jihad Desa Sei Rampah tergolong rendah yaitu dari 15 orang anak baru 3 orang anak $(20 \%)$ saja yang mampu menyebutkan lambang bilangan, berhitung dan menghubungkan lambang bilangan 1-10 sesuai indikator standar tingkat pencapaian perkembangan anak dan sisanya sebanyak 12 orang anak (80\%) belum mampu menyebutkan lambing bilangan 1-10, dilihat dari hasil ketuntasan belajar anak, sehingga peneliti merencanakan perbaikan pembelajaran dengan melaksanakan siklus I.

Berdasarkan hasil penelitian dapat dilihat bahwa dari 15 orang anak pada siklus I di pertemuan ke 5 pesentase nilai rata-rata kelas masih 68\%. Dan nilai ketuntasan belajar anak masih 47\%. Pada siklus I kemampan berpikir simbolik mengenal lambang bilangan
1-10 terus mengalami peningkatan, tetapi peningkatannya tidak signifikan dan belum menyentuh angka 75\% dari ketuntasan belajar anak. Hal ini dapat disebabkan karena guru kurang sepenuhnya menguasai materi pembelajaran, media yang digunakan kurang menarik bagi anak dan juga disebabkan karena kegiatan bermain belum pernah dilakukan sebelumnya yaitu bermain dengan menggunakan media stick angka, sehingga perlu dilakukan perbaikan di siklus II.

Berdasarkan hasil penelitian dapat dilihat bahwa dari 15 orang anak pada siklus II di pertemuan ke 5 pesentase nilai rata-rata kelas 88\%. Dan nilai ketuntasan belajar anak sudah mencapai 93\%. Pada siklus II ini dapat dilihat bahwa kemampuan berpikir simbolik anak sudah menunjukan hasil yang sangat baik dimana persentase keberhasilan belajar anak telah mencapai $75 \%$ ketuntasan belajarnya. Ada beberapa faktor yang menyebabkan meningkatnya kemampuan berpikir simbolik anak dapat mengenal lambang bilangan diantaranya metode dan materi pembelajaran yang menarik bagi anak, penjelasan dengan bahasa yang mudah diterima oleh anak dan media yang digunakan lebih baik lagi dari sebelumnya sehingga anak lebih tertarik, senang dan berminat melaksanakan kegiatan pembelajaran. Peneliti telah berhasil memperbaiki setiap kegiatan pembelajaran, sehingga kemampuan berpikir simbolik anak menyebutkan, berhitung dan menghubungkan lambang bilangan 1-10 melalui bermain dengan menggunakan media stick angka di kelompok B TK Islam Al Jihad mengalami peningkatan sesuai dengan yang diharapkan, kegiatan pembelajaran telah berhasil secara maksimal. Dengan keberhasilan ini maka tidak perlu dilaksanakan siklus selanjutnya

\section{SIMPULAN DAN SARAN}

Berdasarkan data hasil penelitian dan perbaikan pembelajaran dapat ditarik kesimpulan bahwa kegiatan meningkatkan kemampuan berpikir simbolik anak melalui 
Jurnal PG-PAUD Trunojoyo : Jurnal Pendidikan dan Pembelajaran Anak Usia Dini, Volume 7, Nomor 2, Oktober 2020 hal 69-74, ISSN : 2528-3553 (online), ISSN: 2407-4454 (print)

bermain dengan media stick angka di kelompok B TK Islam Al Jihad Desa Sei Rampah berhasil dilaksanakan dengan hasil akhir nilai rata-rata kelas $88 \%$ dan nilai ketuntasan belajar 93\%, kegiatan dilaksanakan dengan tahapan-tahapan yang ada dalam PTK yaitu tahap perencanaan, pelaksanaan, pengamatan dan refleksi yang termuat dalam kegiatan siklus. Kegiatan penelitian ini dilaksanakan dalam II siklus yang dilaksanakan pada semester genap tahun pelajaran 2018-2019 yang disusun dan dilaksanakan dengan bantuan guru kelas. Kesimpulkan dari kegiatan penelitian ini adalah peneliti telah selesai melakukan kegiatan penelitian dengan hasil sesuai yang diharapkan dan selanjudnya dapat ditingkatkan agar lebih baik lagi.

Berdasarkan hasil perbaikan pembelajaran yang diteliti, peneliti memberi saran dan tindak lanjut yang dapat dilakukan sebagai berikut :

1. Penerapan kegiatan pembelajaran khususnya meningkatkan berpikir simbolik anak mengenal lambang bilangan dapat dikembangkan oleh guru untuk menjadi pembelajaran yang menyenangkan, menarik, bermakna dan mudah dipahami anak.

2. Guru diharapkan mampu menguasai materi dan metode yang akan digunakan sebelum melakukan kegiatan pembelajaran sehingga hasil yang diperoleh memuaskan.

3. Guru menilaisetiap proses kegiatan yang dilakukan oleh anak.

4. Guru memberikan reward kepada anak yang berhasil dalam pembelajaran.

5. Memberikan motivasi, penguatan dan dorongan sangatlah diperlukan untuk mendukung dan memberi rangsangan kepada anak.
6. Melakukan refleksi dan perbaikan setelah melakukan kegiatan pembelajaran.

\section{DAFTAR PUSTAKA}

Abubakar, S. R., Pabunga, D. B., Rahayu, E., Hijau, K., \& Tridharma, B. (2018). Penggunaan Media Stik Angka Berwarna Alam. 1(1), 250-258.

Amiran, S. (2016). Efektifitas Penggunaan Metode Bermain Di Paud Nazareth Oesapa. Jurnal Pendidikan Anak, 5(1). https://doi.org/10.21831/jpa.v5i1.12367

Astuti, H. P. (2013). Smart Parenting: Upaya Peningkatan Kemampuan Kognitif Dan Kreativitas Anak Di Kelurahan Banjarjo, Boja, Kendal. Rekayasa, 11(2), 117-126. https://doi.org/10.15294/rekayasa.v11i2. 10317

Ayu, G., Wulan, N., \& Priatna, D. (2011). Permulaan Anak Usia Dini Melalui Media Permainan Stick Angka.

Ayuni, D., \& Setiawati, F. A. (2019). Kebun Buah Learning Media for Early Childhood Counting Ability. Jurnal Obsesi: Jurnal Pendidikan Anak Usia Dini, $3(1)$, 1. https://doi.org/10.31004/obsesi.v3i1.128

Bodedarsyah, A., \& Yulianti, R. (2019). Meningkatkan Kemampuan Berpikir Simbolik Anak Usia Dini Kelompok a (Usia 4-5 Tahun) Dengan Media Pembelajaran Lesung Angka. CERIA (Cerdas Energik Responsif Inovatif Adaptif), 2(6), 354. https://doi.org/10.22460/ceria.v2i6.p354358

Farhurohman, O. (2017). Hakekat Bermain dan Permainan Anak Usia Dini di Pendidikan Anak Usia Dini (PAUD). 2(1), 27-36.

Gandana, G., Pranata, O. H., \& Yulia Danti, T. Y. (2017). Peningkatan Kemampuan Mengenal Lambang Bilangan 1-10 melalui Media Balok Cuisenaire pada 
Jurnal PG-PAUD Trunojoyo : Jurnal Pendidikan dan Pembelajaran Anak Usia Dini, Volume 7, Nomor 2, Oktober 2020 hal 69-74, ISSN : 2528-3553 (online), ISSN: 2407-4454 (print)

Anak Usia 4-5 Tahun di TK AtToyyibah. Jurnal Paud Agapedia, 1(1), 92-105.

https://doi.org/10.17509/jpa.v1i1.7160

Hardiyanti, L., Sasmiati, \& Sabdaningtyas, L. (2018). Penggunaan Mediadan Kemampuan Berpikir Simbolik Anak Usia Dini. 39(4), 274-287.

Hasnida. (2014). Analisis Kebutuhan Anak Usia Dini. Jakarta: PT. Luxima Metro Media. Jakarta: PT. Luxima Metro Media.

Mutiah. (2010). Psikologi Bermain Anak Usia Dini. Jakarta: Kencana Prenada Media Group.

Nuryani, W. (2020). Hubungan antara Kegiatan Usap Abur dengan Kemampuan Motorik Halus Anak Usia Dini. (JAPRA) Jurnal Pendidikan Raudhatul Athfal (JAPRA), 2(2), 65-73. https://doi.org/10.15575/japra.v2i2.9730

Yulianti, D. (2010). Bermain Sambil Belajar Sains di Taman Kanak-kanak. Jakarta: Indeks. 